\title{
Game of regional environmental policy: Europe and US
}

Article

Accepted Version

Asproudis, E., Khan, N. and Korac-Kakabadse, N. (2019) Game of regional environmental policy: Europe and US. Journal of Industry, Competition and Trade, 19 (1). pp. 1-20. ISSN 1566-1679 doi: https://doi.org/10.1007/s10842-0180274-7 Available at https://centaur.reading.ac.uk/76165/

It is advisable to refer to the publisher's version if you intend to cite from the work. See Guidance on citing.

To link to this article DOI: http://dx.doi.org/10.1007/s10842-018-0274-7

Publisher: Springer

All outputs in CentAUR are protected by Intellectual Property Rights law, including copyright law. Copyright and IPR is retained by the creators or other copyright holders. Terms and conditions for use of this material are defined in the End User Agreement.

\section{www.reading.ac.uk/centaur}

\section{CentAUR}

Central Archive at the University of Reading

Reading's research outputs online 


\title{
Game of Regional Environmental Policy: Europe and US
}

\author{
Elias Asproudis ${ }^{1}$ \\ University of Swansea \\ Nadeem $\operatorname{Khan}^{2}$ \\ University of Reading \\ Nada Korac-Kakabadse ${ }^{3}$ \\ University of Reading
}

\begin{abstract}
We analyse a different timing implementation of environmental regulation and compare the effects on the markets from a policy innovation perspective. The paper addresses the question: Should a regulator try to commit to a policy (ex-ante regulation) or rather adapt its policy to a firm's decisions (ex-post)? The findings are of interest towards improving regulatory effectiveness and economics efficiencies, e.g. for the transatlantic regional relationship between EU and USA. Our findings highlight differences in policy timing between markets may be harmful. The transatlantic regulators should consider the timing of the policy innovation for the achievement of mutual benefits.
\end{abstract}

keywords: regulation; policy innovation; timing, transatlantic agreement

\footnotetext{
${ }^{1}$ University of Swansea, School of Management, Department of Economics, Bay Campus, Fabian Way, Swansea, SA1 8EN United Kingdom. Email: Ilias.Asproudis@swansea.ac.uk

${ }^{2}$ Henley Business School, University of Reading, United Kingdom. e-mail: nadeem.khan@henley.ac.uk

${ }^{3}$ Henley Business School, University of Reading, United Kingdom. e-mail: n.kakabadse@ @enley.ac.uk
} 


\title{
Game of Regional Environmental Policy: Europe and US
}

February 8, 2018

\begin{abstract}
We analyse a different timing implementation of environmental regulation and compare the effects on the markets from a policy innovation perspective. The paper addresses the question: Should a regulator try to commit to a policy (ex-ante regulation) or rather adapt its policy to a firm's decisions (ex-post)? The findings are of interest towards improving regulatory effectiveness and economics efficiencies, e.g. for the transatlantic regional relationship between EU and USA. Our findings highlight differences in policy timing between markets may be harmful. The transatlantic regulators should consider the timing of the policy innovation for the achievement of mutual benefits.

keywords: regulation; policy innovation; timing, transatlantic agreement
\end{abstract}




\section{Introduction}

Environmental impact is a central priority concern of the advanced market regulators, in their policy development and decision making (e.g. Hiriart et al., 2004; Kolstad, et al., 1990; Innes and Bial, 2002; Puller, 2006). Economic modelling attempts to account for externalities in optimising between alone and combined ex-ante and ex-post regulatory effects. However, inefficiencies such as disclosure of private information or negligence about the level of harm, indicate a dynamic relationship between ex-ante / ex-post regulation and firm / regulator (see for example Shavell, 1984).

In this spirit, a number of studies have been focus on the case of the expost versus ex-ante (for some representative studies see Shavell, 1984; Kolstad et al., 1990; Hiriart et al., 2004). Mainly these papers have focus on the case where ex-ante regulation aims to regulate before the existence of possible externalities (damages) and ex-post regulation aims to the correction of the damage or possible externalities. They have introduced the threat of suit or penalty in the ex-post case for the firms for the damage that they caused. Moreover, these studies aim to to choose the less costly policy regulation (Kolstad et al., 1990) and they conclude that a joint ex-post and ex-ante policy is the most often case. Furthermore, the regulator's decision is based on the expected sum of the cost care and harm done (e.g. Shavell, 1984). However, in our paper we compare the two policy timing cases and we focus on the impact of each case on the level of the anti-pollution technology as well as on the imperfect competition issue. Our paper contrary to Shavell (1984) and Kolstad et al., (1990) explores a model where both regulator and firms have perfect information and there is not uncertainty. Therefore, like in Innes and Bial (2002) we assume a welfare maximising government where the social welfare and the regulator's decision is based on the consumer surplus, producer surplus and the level of the environmental damage.

Much of the extant literature isolates the public policy effects to technological diffusion (Jaffe and Stavins, 1995) or narrow economic impacts of 
policy on firm productivity, labour and other fragmented growth factors as performance (Berman and Bui, 2001). In reality, the decision to invest in green anti-pollution technology emerges where regulator and firm have varied market powers within imperfect competition, yielding mixed results for the regulator, firm and environment (Shadbegian and Gray, 2006). Further, the domestic market model and its competitive structures (Montero, 2002) impact beyond borders (Tobey, 1990) where different governance models may affect each other cross-nationally (Holzinger et al., 2008; Conyon et al., 2011). Hence, the issue of environment needs to be understood as a complementary, longer term and regional international regulatory issue (Goulder and Mathai, 2000; Flores et al., 2013) that practically affects diverse stakeholders (Freeman et al., 2007).

Requate's (2005a: 181:188) analysis of existing models and their features notes limitations of policy instruments and concludes a gap in modelling for ex-ante/ex-post timing of regulatory behaviour. The shortcoming is a lack of attention to the output market ... 'it is necessary to account for firm decision on output' (Requate, 2005a:193). Thus, the authors of this paper consider both regulator and firm where, '...this basically boils down to the question about who is the first to move, the regulator or firm?' (Requate, 2005a:179).

The paper focus is from a regulatory perspective and contributes to a gap in environmental policy research that focuses on modelling the timing of decisions between the regulator (Governmental authority) and the firm (Parry et al., 2003; Requate, 2005a). We address an interesting question: Should a regulator commit to a policy (ex-ante) or rather adapt its policy to a firm's decisions (ex-post)? This is of particular importance in cases of market power, where the timing of the regulatory decisions will alter a firm's strategic incentives. Particularly, the ex-ante regulation would allow policy to lead market innovation in contrast with the ex-post regulation where the regulator will allow firms to innovate and then he sets the regulatory standards. In our modelling, we outline the monopoly and oligopoly case as 
important cases of market power (for similar approaches see Innes and Bial, 2002 and Puller, 2006) .Specifically we aim to analyse the economic effects arising from the market power under the existence of negative externalities, technological choice and alternative policy timing for which there is a gap in the literature and which is important from a policy making perspective.

Our paper differs from previous studies with respect to the characteristics of the model and to the way that the regulator could prioritize the environmental protection in the political agenda. Specifically, we introduce a weight in the social welfare equation which represents the priority that the regulator could give to his political agenda in favour of the environmental protection and against to the producer surplus (and vice versa). Also, we assume decreasing returns to scale and a spectrum of possible technologies available to the firms which (directly) are not connected with the level of the production. Furthermore, we compare two different cases of market power (monopoly and oligopoly) and we conclude that the market structure should be taken into account by the regulator in order to design the timing of the policy. Our results have implications for the timing of the policy regulation.

Timing of the policy is an important issue which has been analysed and modelled from different perspectives (Van den Bergh, 2013; Bibas et al. 2015). Following these frameworks, we focus on the environmental antipollution technology under the presence of regulator and firms. We analyse two possible cases with respect to the timing of the decisions. In the first case, ex-ante model, the regulator decides for the environmental technology before the firm's decision for the production level. Hence, the government is committed to an environmental policy and sets the level of environmental friendly technology. This describes the case where the regulator uses command and control policy as efficiency standards (e.g. emissions per unit of output) that can only be met by a single and/or specific technology (for pollution standards see for example Helfand, 1991) - as exemplified in recent government policy towards U.K. diesel cars in major cities. In the second 
case, ex post model, the firm decides for the output and then the regulator sets the level of the new anti-pollution technology. In such case, the firm is innovative e.g. fracking for oil or industry emissions $\mathrm{CO}_{2}$ taxation; and the government adopts a reactive quick response to issues of harm as negative externalities in the market (see Denicolo, 1999 and Requate, 2005b).

By using a simple game theory model, we analyse how divergences between regulator / firm timing, when enforcing and/or implementing environmental regulation, can impact on social welfare and firm economic strategy and efficiency. The theoretical results highlight implications for market efficiencies and environmental effectiveness. In consideration, our findings have practical application to international trade treaties such as the transatlantic regional relationship/negotiations between EU and USA where different policy timings are observed (e.g. Vogel, 2003). More recently, for the case of U.K. Brexit negotiations with the European Union.

The game and its analysis can be summarized as: There is a social welfare maximizing regulator who attaches a weight (or priority) to consumer and producer surplus and therefore faces a trade-off between the benefits of output production and its negative externality. The regulator's weight on each is exogenously given and not part of a broader political process. A firm faces a demand for its product and decides its profit-maximizing output level subject to (i) existing regulation (ex-ante scenario) or ii) expected regulation (ex-post scenario). There is no uncertainty and the game is solved by backward induction to find the SPNE. The analysis discusses comparative statics and varies the market structure (monopoly, oligopoly).

Under the monopoly case, in the ex-ante case the regulator will incentivise reduced environmental damage through policy. If the size of the market is relatively large, the regulator will strongly prioritize environmental protection in order to achieve higher social welfare. Moreover, there is a U-shape relation between the social welfare and the level of the weight/priority that the regulator attaches to the surpluses. Hence, the regulator should strongly 
prioritize the environmental protection (and against to the producer surplus) in the poltical agenda in order to reach higher social welfare. Additionally, in the ex-ante case the anti-pollution technology is more environmentally friendly but more expensive compared with the ex-post case. Furthermore, firm will have lower profit but higher production level, compared with expost case in which early adopter firm will have higher profit. An important difference of the monopoly with the oligopoly market is that in the later market the level of the damage parameter determines if the technology is more or less environmental friendly under the ex-ante compared with the ex-post regulation. In other words, the market structure is an important factor to determine the regulator's decision with respect to the timing of the policy. The different timing of the policy for decisions may drive to economic asymmetries within the firms in industry and between two countries/economies, influencing loss of competitive power and reduction of the global (or common) market share.

Simply, leading firms under the ex-post case will have greater "benefits" and gains rather than under the ex-ante case, which may be an important reason for possible unstable and unsustainable policy agreement between countries and in international firms partnerships or mergers.

From a regulatory policy perspective we argue that it is essential to critically examine the diversity effect of the policy timing in order to achieve common policy effects between different countries/partnerships which may better drive towards more sustainable win-win situations promoting common and shared bilateral benefits.

The remainder of this paper is structured as follows: The proceeding section analyses policy innovation diversity and the transatlantic regional relationship between EU and USA. Next, the set up of the basic two-stage model is explained as firm/regulator and solved for the monopoly case. The comparison of the results is included before, robustness checking of the basic model, with an extension i.e. the case of oligopolistic competition. Finally, 
the discussion and conclusion considers the regulatory perspective of policy timing, whilst calling for further competitive industry level studies to support our findings.

\section{E.U. and U.S. Federal Relations}

The transatlantic regional agreement/negotiations is used as an illustration or example where the results from the theoretical model can be useful for these type of international policy and economic agreements. Therefore, this section includes the necessary information for the transatlantic relations which are helpful for the reader to understand the relation between the theoretical model and the transatlantic regional relation.

The U.S. and Europe have direct investments of $\$ 3.7 \mathrm{tn} / € 2.8 \mathrm{tn}$ in each other with bilateral trade amounting to $\$ 2.7 \mathrm{~m} / € 2.0 \mathrm{~m}$ per day (High Level Work Group, 2013). The Transatlantic economy, valued at $\$ 5 \mathrm{tn}$, accounts for forty percent of global G.D.P. by purchasing power; thirty percent of world trade; and more than fourteen million interdependent jobs (Hamilton and Quinlan, 2011). Most recently, official negotiations have resumed on the Transatlantic Trade and Investment Partnership (T.T.I.P.) which on completion will be the biggest trade deal in the history of the world. Most recently a 15th round of negotiations took place during 3rd-7th October 2016 in New York.

The current delicate global growth of $2.5 \%$ is led by Asia (United Nations, 2012) whilst Europe and U.S. have stabilised from the shock of the transatlantic crisis (van Essen et al. 2013). There has been an excessive reliance in recent decades on overleveraged financial markets (Kakabadse and Kakabadse, 2012) in favour of the shareholder model (Friedman, 1962) which is due a capitalistic rebalance in support of its wider stakeholders (Freeman et al. 2007). The U.S. / European bilateral circumstance represents a call for new multi-level business / socio- technological models (Flores et al. 2013; 
Onetti et al. 2012) and regulatory governance regimes (Conyon et al. 2011). As this is not an isolated phenomenon, the crafting of innovative policies and agendas is best understood by comparing and contrasting the federal structures and stakeholders of these advanced regulatory regional economies (Baldwin, 2011).

In this respect, scholars of comparative governance (van Essen et al. 2013; Aguilera and Jackson, 2003) environmental and consumer regulation (Vogel, 2003); federal fiscal structures (Henning and Kessler, 2012); lobbying (Coen, 1999); corporate social responsibility (Matten and Moon, 2008); and even organisational scandals (Soltani, 2013) debate the salient diversity / convergence between the Continental European and neo-liberal Anglo-American capitalistic models (Kakabadse et al. 2013). The notion of European integration and globalisation (Farazmand, 1999) are often differently understood by national policy makers within the supranational entity of Europe (Hay and Rosamond, 2002). Thus the need remains to harmonise multi-level diversity (Borzel and Risse, 2000) between society, institutions and businesses (Shaffer, 1995) for mutual benefit and common good.

Our paper proceeds by engaging a policy innovation lens to compare and contrast the U.S. and European markets and their stakeholders. Noting cyclical irregularities, we focus attention on policy timing between regulator (Government) and firms within each market across the regions. To achieve balance as common good, there is a need to understand the diversity and synchronise this so that policy outcome impacts can be mutually most effective. We engage a two stages game under two different scenarios to model the behavioural conflict, co-operation and trade-offs between players at the regional level. The emerging findings from our unique conceptualisation of regulatory structures and stakeholders are used to make recommendations that could harmonise or improve the diverse strategic interests of the players across this transnational-transatlantic market. 


\section{Two stage basic model: timing of the deci- sion}

As it was discussed in the above section, U.S / E.U. markets are shaped by their regulator (Government) and the functioning of other stakeholders such as firm. In this respect, the diversity of transatlantic regional relations focuses our attention on the difference in timing of regulatory decision. Therefore in this section, we proceed with analysis of this using a two stage model game with two cases. Our scenario posits that the regulator (Government) has to decide for introducing new greener environmental technology in the spirit of command and control environmental policy instruments. ${ }^{1}$ We introduce a simple model with two strategic players: the firm and the government. Two possible cases are considered with respect of the timing of the model. In the ex-ante case the regulator moves first and sets the expected standard (technology, quality, fines) for the best available environmental technology; a command and control policy. ${ }^{2}$ Then, the firm decides for the level of output. In the ex-post case the firm first decides for the output level. Then, the regulator decides for the anti-pollution technology. ${ }^{3}$.

Ex-ante and ex-post scenario represent a different possible case of the E.U. and U.S. regions (or some economic sectors) as described earlier. This scenario posits that the regulator has to promote the adoption of a green technology through policy decision-making mechanisms, e.g. RandD grants, subsidies, legislative development. In modelling, change is captured either as promotion (by regulator) or adoption (by firm) of green technologies.

In our model we assume that the firms will pollute the environment when

\footnotetext{
${ }^{1} \mathrm{~A}$ possible extension could be the case of the emission permits. For the case of environmental taxes see Innes and Bial, 2002.

${ }^{2}$ For examples of innovation policy instruments see Borras and Edquist, (2013).

${ }^{3}$ A similar approach is followed by Khan et al., (2014) under an informal analysis and for the case of the renewable energy in a monopoly market. In our case we focus on the case of the environmental anti-pollution technology and we analyse a formal model under monopoly and oligopoly markets.
} 
they produce goods. The quantity of pollution depends upon the level of output (e.g. quantity of diesel fuel produced in a refinery) and efficiency of the environmental technology (e.g. reduction of $\mathrm{CO}_{2}$ emissions). The firm's level of emissions is $y=k q$ where $y$ is the emissions $(y>0), k$ is the technology and $q$ the level of the production $(q>0)$. Contrary to Innes and Bial (2002) we do not assume that the emissions fall with the improvement of the environmental technology, neither increased. Technology $k \in(0,1]$ is characterised within a spectrum of values ranging between 0 and 1 . The greener and less polluting the technology, the closer to 0 the value will be. The more polluting the technological choice, the closer the value is to 1 . The absence of an ideal technology that eliminates all emissions is assumed (i.e. we cannot take values equal to 0$){ }^{4}$

The damage function $(D F)$ represents the damage to the environment, $D F=e y$, where $e(e>0)$ is the damage parameter (e.g. the damage that one tonne of $\mathrm{CO}_{2}$ will cause to the environment) $)^{5}$.

Furthermore, it has been assumed that the players have perfect information. We solve the model with backward induction in order to calculate the Sub-game Perfect Nash Equilibrium (SPNE).

\subsection{The regulator}

The regulator aims to maximize the social welfare $(S W)$ which is represented in a simple form by the equation $S W=C S+P S$ where $C S$ is consumer surplus and $P S$ is producer surplus. Moreover, the regulator will set the level of acceptable environmental technology or the best available environmental technology $k$ to maximize the $S W$. The regulator attaches a weight to consumer surplus, producer surplus and negative externalities, This weight is introduced in the model using the parameters $(b, 1-b)$. The parameter

\footnotetext{
${ }^{4}$ The set up of the technology is adopted from Asproudis and Gil Molto, 2014 and 2015.

${ }^{5}$ For similar damage function see Kennedy (1999), Kennedy and Laplante (1999) and Requate (2005a).
} 
$b$ represents the regulator's level of interest or priority (in the regulator's agenda) for the environmental protection plus the $C S$ and $1-b$ represents the priority for producer surplus. Hence, there is a trade - off between the priorities for the two targets or simply the regulator could give more priority in favour to the $P S$ (benefits of output production) but against to the environment and $C S$ and vice versa. ${ }^{6}$

Finally, the decision with respect to the environmental technology is strongly connected with the damage that will happen to the environment during the production process of the good. Therefore, the social welfare is:

$$
S W=b(C S-D F)+(1-b) P S
$$

where $b \in(0,1)$.

\subsection{The firm}

The firm's target is to maximise the profits and is characterised by the cost function

$$
C=c q^{2}+(1-k)^{2}
$$

where $c$ is the unit cost of $q^{2}$ and $(1-k)^{2}$ is the technological cost. Simply, the greener the technology the lower the value of $k$, but the technology will be more costly for the firm. In the opposite case, the higher the value of $k$ the more polluting the technology is, but the lower the adoption cost. Besides, the quadratic version indicates the diminishing returns to investment for the

\footnotetext{
${ }^{6}$ The trade-off between the two (regulator's) priorities is close to the reality and represents this case where one could be better off if someone else will be worst off. Furthermore we assume $b \in(0,1)$, thus there are not extreme priorities.
} 
technology and decreasing returns to scale for the output. ${ }^{7}$,

Additionally, the firm's revenues are equal to $p q$ where $p$ is the price of the good in the market and equal to the inverse demand function:

$$
p=a-q
$$

with $a(a>0)$ the size of the market. Hence, the firm's profits is given by

$$
\Pi=p q-c q^{2}-(1-k)^{2}
$$

After the necessary calculations we take the results with respect to output, technology, profits, prices, social welfare and emissions which are presented in the table below ${ }^{9}$

\begin{tabular}{|c|c|c|} 
& Ex-Ante & Ex-Post \\
\hline $\bar{q}$ & $\frac{a}{2(1+c)}$ & $\frac{2 a}{4+4 c+\frac{b^{2} e^{2}}{(b-1)^{2}}}$ \\
\hline $\bar{k}$ & $1-\frac{a b e}{4(1-b)(1+c)}$ & $1-\frac{a(1-b) b e}{4(b-1)^{2}(1+c)+b^{2} e^{2}}$ \\
\hline $\bar{\Pi}$ & $\frac{a^{2}\left(1-\frac{b^{2} e^{2}}{4(b-1)^{2}(1+c)}\right)}{4(1+c)}$ & $\frac{a^{2}(b-1)^{2}}{4(b-1)^{2}(1+c)+b^{2} e^{2}}$ \\
\hline $\bar{p}$ & $a-\frac{a}{2(1+c)}$ & $a-\frac{2 a}{4+4 c+\frac{b^{2} e^{2}}{(b-1)^{2}}}$ \\
\hline$S \bar{W}$ & $\frac{-a A+a^{2} b^{2} e^{2}}{16(b-1)(1+c)^{2}}$ & $\frac{a(b-1)^{2}(X+Y)}{\left(4(b-1)^{2}(1+c)+b^{2} e^{2}\right)^{2}}$ \\
\hline $\bar{y}$ & $\frac{a(4(b-1)(1+c)+a b e)}{8(b-1)(1+c)^{2}}$ & $2 a(b-1)^{2}\left(\frac{1}{L}+\frac{a(b-1) b e}{L^{2}}\right)$ \\
\hline
\end{tabular}

\footnotetext{
${ }^{7}$ In our paper and contrary to Asproudis and Gil Molto (2015) we assume decreasing returns to scale. The "Quadratic cost functions reflect decreasing returns to scale or diseconomies of scale and are frequently met in applications, for instance in the modeling of renewable resources exploitation" Dubiel-Teleszynski, T. (2011). Also the decreasing returns to scale could represent the "limited supply of industrial land and buildings" like in the case of Singapore's manufacturing sector (Kee, 2002).

${ }^{8}$ Following Asproudis and Gil-Molto (2015), the technological cost is not connected directly with the production level but with the anti-pollution technology. For example, this could be the case of the number of the filters in the smokestack or the number of catalysts in the cars (for similar cases see Keohane, 2002; Chao and Wilson, 1993 and Srivastava et al., 2001).

${ }^{9}$ All the steps of the two models and the analogous calculations are available to the reader and are included in the appendix.
} 
where $A=(b-1)(2 a(2 c(b-1)+b-2)+8 b(1+c) e), X=-8(b-$ $1)^{2} b(1+c)-2 b^{3} e^{3}, Y=a(b-1)\left(-2(b-1)(b-2+2(b-1) c)-3 b^{2} e^{2}\right)$ and $L=4(b-1)^{2}(1+c)+b^{2} e^{2}$

\subsection{Comparison}

Since we have the results from the previous section we are in position to calculate and characterise the differences of the two cases.

\subsubsection{Price and output}

After the calculation $p_{1}-p_{2}<0$ (where the subscript 1, 2 represents the ex-ante and ex-post scenario respectively) the result is negative, so the price of the good in the second case is higher than in the first or the consumers will pay more in the second scenario $p_{1}<p_{2}$. Similarly, we calculate the algebraic difference of the outputs/level of production $\left(q_{1}-q_{2}>0\right)$ where the result is positive. So, in the first case where the regulator moves first the firm will produce more than in the second case where the regulator moves second.

Lemma 1 If the regulator moves first and decides the level of the environmental technology (ex-ante), then the production rises and the consumers pay less for the good than if the regulator moves second (ex-post). ${ }^{10}$

\subsubsection{Technology and profits}

We calculate the difference on the technologies' values, $k_{1}-k_{2}<0$, hence the firm in the second scenario will use more polluting technology. If the regulator moves first and sets the technological level, then the firm will adopt a greener technology than in the opposite case. However, adopting a greener technology drives the firm to lower profits. Specifically, the analogous calculation for

\footnotetext{
${ }^{10}$ See the appendix for the proof of Lemma 1.
} 
the profits gives that the firm has more profits under the ex post scenario $\left(\Pi_{1}-\Pi_{2}<0\right)$ where the firm will move before setting the technological level by the regulator than, under the ex-ante case.

Lemma 2 Under the ex-ante case the firm will adopt a less polluting technology but will achieve lower profit levels rather than under the ex-post case. ${ }^{11}$

From both Lemmas (1 and 2) we observe that; the firm will choose a higher level of production in response to greener technology requirements imposed ex-ante but this could drive to lower level of profits (than it could be when the firm sets production level prior to learning of a less-green regulation, ex-post). The explanation of these two results is based on the characteristics of the firm and specifically on the decreasing returns to scale in production. Hence, in this case the adoption of a better technology is not necessary profitable for the firm or in other words the introduction of a new technological level from the regulator may have a negative impact on the specific - decreasing returns to scale - firm's profits.

\subsubsection{Emissions and environmental damage}

With respect to the emissions we have that

$$
\begin{array}{ll}
\bar{y}_{1}> & \bar{y}_{2} \text { if } a<a_{c v} \\
\bar{y}_{1}< & \bar{y}_{2} \text { if } a>a_{c v}
\end{array}
$$

where $a_{c v}=\frac{4(b-1)(1+c)\left[\left(-4(b-1)^{2}(1+c)-b^{2} e^{2}\right)\right]}{8(b-1)^{2} b(1+c) e+b^{3} e^{3}}>0$ is a critical value with respect to the market's size. Hence, the results depend on the market size and there are two effects behind this result. Specifically, under the ex-ante case the firm will adopt less polluting technology compared with the ex-post case, therefore the greener technology will drive to lower level of emissions (first effect). However, under the ex-ante case the firm will produce more than

\footnotetext{
${ }^{11}$ See appendix for the proof of Lemma 2.
} 
under the ex-post case so, will pollute more (second effect). Thus, for $a<a_{c v}$ the second effect dominates the first but for $a>a_{c v}$ the first effect dominates the second (the decreasing of the emissions from the adoption of the greener technology is more than the increasing of the emissions from the rising of the production).

Since the environmental damage is equal to $D F=e y$, the results with respect to the damage functions $\left(D F_{1}, D F_{2}\right)$ are symmetrical with the emissions $\left(y_{1}, y_{2}\right)$ respectively and the critical value is the same. Therefore, $\overline{D F_{1}}>\overline{D F_{2}}$ for $a<a_{c v}$ and $\overline{D F_{1}}<\overline{D F_{2}}$ for $a>a_{c v}$.

Lemma 3 There is a critical value $a_{c v}$ for the market's size where i) for $a<a_{c v}$ the emissions (and the environmental damage) are more under the ex-ante case ii) for $a>a_{c v}$ the emissions (and the environmental damage) are more under the ex-post case. Thus, for a relatively small market's size the damage to the environment is more if the regulator moves first and sets the environmental technology level before the firm's production.

\subsubsection{Social Welfare}

The social welfare depends on the market size. There is a critical market size value which impacts the social welfare. Specifically,

$$
\begin{array}{ll}
S \bar{W} W_{1}> & S \bar{W}_{2} \text { if } a>a^{c v} \\
S \bar{W}_{1}< & S \bar{W}{ }_{2} \text { if } a<a^{c v}
\end{array}
$$

where the $a^{c v}=-\frac{8(b-1)(1+c) e\left[(b-1)^{2}(1+c)+b^{2} e^{2}\right]}{-16(b-1)^{3}(1+c)+2(b-1) b(-6+5 b+6(b-1) c) e^{2}+b^{3} e^{4}}>0$.

Lemma 4 For relatively large size of the market $\left(a>a^{c v}\right)$ the social welfare is higher under the ex-ante case but for relatively small market's size the ex-post case drives to higher social welfare. 


\subsection{Comparative Statics}

In this section we use comparative statics to export and analyse the previous results. Specifically, from the ex-ante scenario we focus on the technological choice and we calculate the differentiation with respect to the parameter $b\left(\frac{\partial \bar{k}_{1}}{\partial b}=-\frac{a e}{4(b-1)^{2}(1+c)}<0\right)$ where the result is negative. Hence, the higher the value of the parameter $b$ (more weight or priority), the greener, less polluting the technology will be. This is not a surprising result since we expect that a higher weight will drive the regulator to choose a greener technology. However, what is interesting is the social welfare calculation with respect to parameter $b$. Particularly,

$$
\frac{\partial S \bar{W}_{1}}{\partial b}=\frac{-a\left(K+a(b-2) b e^{2}\right)}{16(b-1)^{2}(1+c)^{2}}=0
$$

where $K=(b-1)^{2}(2 a(1+2 c)+8(1+c) e$. We are solving with respect to the parameter $b$ and we get the critical value, $b_{c v}=1-\frac{a e^{2}}{\sqrt{a e^{2}\left(8(1+c) e+a\left(2+4 c+e^{2}\right)\right)}} \cdot 12$ The $b_{c v}$ determines if the social welfare is increasing or decreasing in the values of $b$. Notable, for $b>b_{c v}$ the $\frac{\partial S \bar{W}_{1}}{\partial b}>0$. The social welfare's behaviour with respect to weight $b$ indicates that a U-Shape relation characterises the $S W$ with respect to the value of the parameter $b$. The intuition behind this is the existence of two effects. Specifically, the increased value of parameter $b$ indicates that the regulator 'strongly prioritises' in the agenda the environmental protection. However, the higher value of $b$ is against profits. Thus, the two effects are:

i) on the one hand the increasing of the parameter $b$ drives to lower profit level, mathematically $\frac{\partial \bar{\Pi}_{1}}{\partial b}=\frac{a^{2} b e^{2}}{8(b-1)^{3}(1+c)^{2}}<0$ since $b<1$ (first effect)

ii) on the other hand, increasing the value of $b$ drives to lower environmental damage, mathematically $\frac{\partial \overline{D F}}{\partial b}=-\frac{a^{2} e^{2}}{8(b-1)^{2}(1+c)^{2}}<0$ (second effect).

\footnotetext{
${ }^{12}$ We set $\frac{\partial S \bar{W}_{1}}{\partial b}=0$ and we solve with respect to $b$, Then, the quadratic form will give two possible solutions. $b_{1}=1-\frac{a e^{2}}{\sqrt{a e^{2}\left(8(1+c) e+a\left(2+4 c+e^{2}\right)\right)}}$ and $b_{2}=1+\frac{a e^{2}}{\sqrt{a e^{2}\left(8(1+c) e+a\left(2+4 c+e^{2}\right)\right)}}$, the second solutions is rejected because $b<1$.
} 
That is, for $b<b_{c v}$, the first effect dominates the second or the damage to profits is larger than reducing the environmental damage and therefore the $S W$ decreases in $b$. However, for $b>b_{c v}$, the second effect dominates the first or the social welfare increases in $b$ because the damage to the environment reduces more than the damage to the firm's profits.

\section{Proposition $1 \quad$ Under the ex-ante model, there is a U-shape} relation between the $S W$ and the value of parameter $b$.

An interesting result is the relation between the technology and the output in the ex-post scenario. Particularly, we use the implicit function theorem based on the partial derivatives with respect to parameter $b$. Initially, we calculate $\frac{\partial \bar{q}_{2}}{\partial b}$ and $\frac{\partial \bar{k}_{2}}{\partial b}$ where from the implicit function theorem we have: ${ }^{13}$

$$
\frac{\frac{\partial \bar{q}_{2}}{\partial b}}{\frac{\partial \bar{k}_{2}}{\partial b}}=\frac{\partial \bar{q}_{2}}{\partial \bar{k}_{2}}=\frac{4(b-1) b e}{-4(b-1)^{2}(1+c)+b^{2} e^{2}}
$$

Solving with respect to the parameter $e$ we get the critical value $e_{c v}=$ $-\frac{2(b-1) \sqrt{1+c}}{b} .{ }^{14}$ The damage parameter's critical value determines if adopting a greener technology will lead to an increase or decrease of the firm's output. Concretely, for $e<e_{c v}$ adopting a more polluting technology (higher the value of $k$ ) will increase the production of the good $\frac{\partial \bar{q}_{2}}{\partial \bar{k}_{2}}>0$. However, for $e>e_{c v}$ the more polluting the technology, the less the level of the production $\frac{\partial \bar{q}_{2}}{\partial \bar{k}_{2}}<0$. This is an interesting result for (both) the regulator (and the firm) who will decide for the level of the technology after the firm's decision for the level of the output.

Proposition $2 \quad$ Under the ex-post case there is a critical value for the damage parameter $e_{c v}$ where; up to the critical value of $e_{c v}$ the more polluting the technology, the larger the production of the good. However,

$13 \frac{\partial \bar{q}_{2}}{\partial b}=\frac{4 a(b-1) b e^{2}}{\left(4(b-1)^{2}(1+c)+b^{2} e^{2}\right)^{2}}<0$, where numerator $<0$ and denominator $>0, \forall b<1$. Also, $\frac{\partial \bar{k}_{2}}{\partial b}=\frac{-4 a(b-1)^{2}(1+c) e+a b^{2} e^{3}}{\left(4(b-1)^{2}(1+c)+b^{2} e^{2}\right)^{2}}$ where denominator $>0$ and numerator $\lessgtr 0, \forall b<1$.

${ }^{14}$ There are two possible solutions; $e_{1}=-\frac{2(b-1) \sqrt{1+c}}{b}$ accepted, $e_{2}=\frac{2(b-1) \sqrt{1+c}}{b}$ rejected $\forall e>0$. 
for the values of damage parameter bigger than the critical value, the more polluting the technology, the less quantity of good the firm will produce.

\section{Oligopolistic case}

In this section for robustness, we extend the basic model (monopoly case) in order to analyse the oligopolistic case. Although the extended model is more complex and the results are characterised by closed form functions we manage to extract some interesting results under the competition case. The calculations for each stage are available on the appendix. Here, we present the important results after the comparison of the two cases (ex-ante and ex-post).

We focus on a duopoly market where the two firms $i, j=1,2, i \neq j$ compete on production level (Cournot) under a homogeneous product but under assymetric cost $c_{i} \neq c_{j}$. The firms face an inverse demand function $p_{i}=a-q_{i}-q_{j}$ and the firm $i$ 's profits equals $\Pi_{i}=p q_{i}-c_{i} q_{i}^{2}-\left(1-k_{i}\right)^{2}$.

\subsection{Comparison}

We compare the results (see appendix) from the previous two cases (ex-ante and ex-post) under a Cournot duopoly competition. The comparison for the case of the price, output, technology, emissions and environmental damage is presented. The superscript $E A$ indicates the ex-ante case and the $E P$ the ex-post case respectively.

Specifically, we calculate $\bar{p}_{i}^{E A}-\bar{p}_{i}^{E P}=-\frac{2 a b^{2} e^{2}\left(2 G^{2}\left(1+2 c_{i}\left(1+c_{i}\right)+2 c_{j}\left(1+c_{j}\right)\right)+b^{2}\left(1+c_{i}+c_{j}\right) e^{2}\right)}{F\left(4 G^{4} F\right)+4 G^{2} b^{2}\left(2+c_{i}+c_{j}\right) e^{2}+b^{4} e^{4}}<$ 0 where $G=b-1, F=3+4 c_{j}+4 c_{i}\left(1+c_{j}\right)$. The results are negative therefore, as in the basic model, under the ex-post scenario the price of the goods is more expensive than under the ex-ante scenario. Similarly, for the technologies $\bar{k}_{i}^{E A}-\bar{k}_{i}^{E P}$ and after the necessary calculation we argue that there is a critical value for the damage parameter $e^{c v}=\frac{\sqrt{2} \sqrt{(b-1)^{2}\left(-1+2 c_{i}-2 c_{j}\left(3+2 c_{j}\right)\right.}}{\sqrt{b^{2}\left(1+2 c_{j}\right)}}$ which 
determines the result from the comparison of the technologies ${ }^{15}$. Hence,

$$
\begin{array}{ll}
\bar{k}_{i}^{E A}<\bar{k}_{i}^{E P} & \text { if } \quad e>e^{c v} \\
\bar{k}_{i}^{E A}>\bar{k}_{i}^{E P} & \text { if } \quad e<e^{c v}
\end{array}
$$

Furthermore, the specific critical value and for the comparison between $\bar{q}_{i}^{E A}$ and $\bar{q}_{i}^{E P}$ we have

$$
\begin{array}{ll}
\bar{q}_{i}^{E A}>\bar{q}_{i}^{E P} & \text { if } \quad e>e^{c v} \\
\bar{q}_{i}^{E A}<\bar{q}_{i}^{E P} & \text { if } \quad e<e^{c v}
\end{array}
$$

Proposition 3 If $e>e^{c v}$ then the technology is less polluting under the ex-ante regulation and the firms produce more than under the ex-post. If $e<e^{c v}$ the firms produce more under the ex-post but the technology is greener than under the ex-ante regulation.

Analogous with the basic model are the results with respect to the emissions and the environmental damage. Particularly, the difference $\bar{y}_{i}^{E A}-\bar{y}_{i}^{E P}$ (and $D F^{E A}-D F^{E P}$ ) depends on the size of the market and the critical value $a_{c v}=\frac{2 G F\left(-4 G^{4} F-4 G^{2} b^{2}\left(2+c_{i}+c_{j}\right) e^{2}-b^{4} e^{4}\right)}{8 G^{4} b\left(1+2 c_{j}\right) F e+2 G^{2} b^{3}\left(7+2 c_{j}\left(7+2 c_{j}\right)+c_{i}\left(6+8 c_{j}\right)\right) e^{3}+b^{5}\left(1+2 c_{j}\right) e^{5}}>0$

$$
\begin{array}{lll}
\bar{y}_{i}^{E A}>\bar{y}_{i}^{E P} & \text { if } & a<a^{c v} \\
\bar{y}_{i}^{E A}<\bar{y}_{i}^{E P} & \text { if } & a>a^{c v}
\end{array}
$$

Lemma $5 \quad$ As in the basic model, the ex-ante case will drive to higher level of emissions for relatively small market size $\left(a<a_{c v}\right)$ but the emissions are greater under the ex-post case for relatively large market size $\left(a>a_{c v}\right)$.

\section{Discussion and Conclusions}

This paper contributes to a gap in environmental policy research that focuses on modelling the timing of decisions between the regulator and the firm.

\footnotetext{
${ }^{15}$ In order to guarantee a real number for the $e^{c v}$ we set $-1+2 c_{i}-2 c_{j}\left(3+2 c_{j}\right)>0$ or $c_{i}>\frac{1}{2}\left(1+6 c_{j}+4 c_{j}^{2}\right)$.
} 
The question is: Should a regulator try to commit to a policy (ex-ante) or rather adapt its policy to a firm's decisions (ex-post)? Hence, by using a simple game theory model, we explore how divergences in the timing when implementing and/or enforcing environmental regulation can impact on the social welfare and firms' economic efficiency. The results are interesting from a government and economic perspective. A possible application of the results is the transatlantic regional relationship/negotiations between EU and USA where different policy timing was observed with EU to follow an ex-ante approach and USA an ex-post style of decisions (Vogel, 2003).

In the ex-ante model the regulator decides for the environmental technology before the firms decision for the production level. In the ex post model the firms decide for the output and then the regulator sets the level of the new anti-pollution technology. Our theoretical findings are discussed below and could have implications for international negotiations like the transatlantic regional negotiations along with how innovations through national policies and regional agreements can impact each other. The concept of this analysis could indeed be applied and generalized to other government cases of policy decision making where the timing of the policy innovation is crucial (e.g. chemical sector, agriculture sector etc.).

We argue that, if the regulator commits to an environmental policy (exante) then environmental technology is more environmental friendly in comparison with the ex-post case. Specifically, under the ex-post regulation the firm is incentivised to adopt the more polluting technology in favour of higher profits. This, we relate to the U.S. market being corporate dominant (Kakabadse and Kakabadse, 2012) and incentivised commercially (Groll and Ellis, 2013). Our findings may offer some insight into the E.U. (ex-ante) and U.S. (ex-post) current dilemmas of policy. Importantly, this could explain why diverse policy innovations persist and their effect needs resolution in favour of a closer U.S.-E.U. relationship through the transatlantic regional agreement/negotiations. 
For the ex-ante model we argue that the social welfare is higher if the regulator will "strongly prioritize" the environmental protection in the political agenda. In that case the technology is more environmental friendly and there are two important effects. The firm's profits will be reduced the less polluting the technology is (effect one); but the damage to the environment is also reducing (effect two). From the regulator's view-point a sacrifice of the profits' in favour of environmental protection is worthy only if the weight or the priority for the environmental protection is high in the political agenda. However, we argue that if the priority is not relatively strong then this may have a harmful impact on social welfare. We suggest this may explain the E.U. over-regulatory impact (Schepers, 2010).

All in all, under a monopoly market, moving from an ex-ante to ex-post regulation has the following consequences: i) the price increases while the production decreases, ii) the environmental technology becomes more polluting which leads to higher profits iii) the emissions and the environmental damage either increase or decrease depending on the market size iv) a similar threshold is introduced for the social welfare. However, in an oligopoly market the damage parameter determines if the technology is more or less environmentally friendly under the ex-ante regulation. This is important for the regulator. The structure of the market could be an important factor to influence the regulator's decision with respect to the timing of the policy. Specifically, under a relatively small level of damage parameter the technology is more environmentally friendly and the production is larger under the ex-post regulation rather than under the ex-ante.

Finally, we encourage further future research on the timing of the regulation since each regulator that seeks to maximise social welfare is influenced by the dynamics and incentives of institutional politics with organisational circumstances, and to a lesser extent by other well-organised pressure groups (Elliott et al., 1985; Grossman and Helpman, 1984). We note here that N.G.O. influence has rising affect within European politics (Vogel, 2003) and 
that European consumers are targets of N.G.O's due to their greater awareness of issues (Spar and La Mure, 2003). The economic modelling of tradeoffs and protectionism as lobbying influences (Marusca and Irimies, 2013; Bandyopadhyay et al., 2012; Weymouth, 2011; Barron, 2011; Holman, 2009; Yackee and Yackee, 2006; Hillman, 2003; Damania and Fredricksson, 2000) by interested parties (Magee, Brock and Young, 1989; Grossman and Helpman, 1994; Bernheim and Whinston, 1986) at certain timings of the decision making process, puts pressure on decision makers and could be an extension to our model under the same or different market structure (e.g.perfect competitionor leader-follower model). 


\section{Appendix}

\subsection{Ex-ante scenario - Monopoly}

\subsubsection{Stage 2: Firm decides on output}

We calculate the First Order Conditions (FOC) ${ }^{16}$

$$
\frac{\partial \Pi_{1}}{\partial q}=a-2 q(1+c)=0
$$

and solving with respect to $q$ the firm's level of production and the analogous profits are

$$
\begin{gathered}
\bar{q}_{1}=\frac{a}{2(1+c)} \\
\Pi_{1}^{*}=\bar{q}_{1}^{2}(1+c)-(k-1)^{2}
\end{gathered}
$$

where the subscript 1 indicates the first scenario (ex-ante).

\subsubsection{Stage 1: Regulator decides for technology}

After the substitution of (6) into (1) we have

$$
S W_{1}^{*}=(b-1)\left[(k-1)^{2}-\frac{a^{2}}{4(1+c)}\right]+\frac{a b(a-4(1+c) e k)}{8(1+c)^{2}}
$$

and from the FOC we obtain ${ }^{17}$

$$
\frac{\partial S W_{1}^{*}}{\partial k}=2(b-1)(k-1)-\frac{a b e}{2(1+c)}=0
$$

yielding the optimum technology

$$
\bar{k}_{1}=1-\frac{a b e}{4(1-b)(1+c)}
$$

\footnotetext{
${ }^{16}$ The Second Order Conditions (SOC) are satisfied $\frac{\partial^{2} \Pi}{\partial q^{2}}=-2(1+c)<0$.

${ }^{17}$ The SOC is $\frac{\partial^{2} S W^{*}}{\partial k^{2}}=2(b-1)$, which is negative since $b<1$.
} 
where $\frac{\partial \bar{k}_{1}}{\partial b}<0$ thus, the technological choice is reducing in $b$ or the higher the value of the parameter $b$ the less polluting the technological choice $k$ is. We substitute all the results to the initial equations and therefore we have the results for the ex-ante case. Particularly, the profits are given by

$$
\bar{\Pi}_{1}=\frac{a^{2}\left(1-\frac{b^{2} e^{2}}{4(b-1)^{2}(1+c)}\right)}{4(1+c)}
$$

and the price of good in the market is

$$
\bar{p}_{1}=a-\frac{a}{2(1+c)}
$$

After substituting the technology to the Social Welfare (8) we obtain:

$$
S \bar{W}_{1}=\frac{-a A+a^{2} b^{2} e^{2}}{16(b-1)(1+c)^{2}}
$$

where $A=(b-1)(2 a(2 c(b-1)+b-2)+8 b(1+c) e)$

Also, the firm's emissions are

$$
\bar{y}_{1}=\frac{a(4(b-1)(1+c)+a b e)}{8(b-1)(1+c)^{2}}
$$

where $\frac{\partial \bar{y}_{1}}{\partial b}<0$ thus, emissions' level is decreasing in $b$. Finally, the damage to the environment is equal to $\overline{D F} F_{1}=e \bar{y}_{1}$ 


\subsection{Ex-post scenario - Monopoly}

\subsubsection{Stage 2: Regulator decides for technology}

The regulator decides on the technological level in order to maximize the social welfare. The FOC is equal to: ${ }^{18}$

$$
\frac{\partial S W}{\partial k}=2(1-b)(1-k)-b e q=0
$$

and solving with respect to $k$ we have

$$
k_{2}^{*}=1-\frac{b e q}{2(1-b)}
$$

where the subscript 2 indicated the ex-post case.

\subsubsection{Stage 1: Firm decides on output}

After the substitution of $k^{*}$ into the profit's equation we have $\Pi_{2}=(a-$ $q) q-c q^{2}-\frac{b^{2} e^{2} q^{2}}{(2 b-2)^{2}}$. As usual we calculate the FOC which is ${ }^{19}$

$$
\frac{\partial \Pi_{2}}{\partial q}=a+\frac{1}{2}\left(-4-4 c-\frac{b^{2} e^{2}}{(b-1)^{2}}\right)=0
$$

and solving for $q$ we calculate the optimum level of output

$$
\bar{q}_{2}=\frac{2 a}{4+4 c+\frac{b^{2} e^{2}}{(b-1)^{2}}}
$$

We substitute $\bar{q}_{2}$ into $k_{2}^{*}$ and then we have the optimum technology for this model

$$
\bar{k}_{2}=1-\frac{a(1-b) b e}{4(b-1)^{2}(1+c)+b^{2} e^{2}}
$$

\footnotetext{
${ }^{18}$ The SOC is negative so, it guaranties the optimum value of $k_{2}^{*}$.

${ }^{19}$ The SOC is negative and equal to $\frac{\partial^{2} \Pi_{2}}{\partial q^{2}}=-2-2 c-\frac{b^{2} e^{2}}{2(-1+b)^{2}}$.
} 
Hence, the final results for the ex post model are; profits equals

$$
\bar{\Pi}_{2}=\frac{a^{2}(b-1)^{2}}{4(b-1)^{2}(1+c)+b^{2} e^{2}}
$$

and price of the good is

$$
\bar{p}_{2}=a-\frac{2 a}{4+4 c+\frac{b^{2} e^{2}}{(b-1)^{2}}}
$$

After the necessary substitutions and calculation we get the Social welfare

$$
S \bar{W}_{2}=\frac{a(b-1)^{2}(X+Y)}{\left(4(b-1)^{2}(1+c)+b^{2} e^{2}\right)^{2}}
$$

where $X=-8(b-1)^{2} b(1+c)-2 b^{3} e^{3}$ and $Y=a(b-1)(-2(b-1)(b-2+$ $\left.2(b-1) c)-3 b^{2} e^{2}\right)$.

The level of the emissions are given by

$$
\bar{y}_{2}=2 a(b-1)^{2}\left(\frac{1}{L}+\frac{a(b-1) b e}{L^{2}}\right)
$$

where $L=4(b-1)^{2}(1+c)+b^{2} e^{2}$. So, the analogous damage function is $\overline{D F_{2}}=e \bar{y}_{2}$.

\subsection{Proof of Lemma 1}

From the calculation of the difference we take $\overline{\mathbf{p}}_{1}-\overline{\mathbf{p}}_{2}=-\frac{\mathbf{a b}^{2} \mathbf{e}^{2}}{2(1+\mathbf{c})\left(4(\mathbf{b}-1)^{2}(1+\mathbf{c})+\mathbf{b}^{2} \mathbf{e}^{2}\right.}$ and it is straightforward that it is a negative result since the numerator and the denominator is positive. Thus, the price is lower under the ex-ante case. Also, we calculate $\overline{\mathbf{q}}_{1}-\overline{\mathbf{q}}_{2}=\frac{\mathbf{a b}^{2} \mathbf{e}^{2}}{2(1+\mathbf{c})\left(4(\mathbf{b}-1)^{2}(1+\mathbf{c})+\mathbf{b}^{2} \mathbf{e}^{2}\right.}$ which is positive since both numerator and denominator are positive. 


\subsection{Proof of Lemma 2}

We calculate $\bar{k}_{1}-\bar{k}_{2}=\frac{a b^{3} e^{3}}{4(b-1)(1+c)\left(4(b-1)^{2}(1+c)+b^{2} e^{2}\right)}$ where the denominator is negative since $b \in(0,1)$, thus the technology is "greener" or less polluting under the ex-ante case.Furthermore, $\bar{\Pi}_{1}-\bar{\Pi}_{2}=-\frac{a^{2} b^{4} e^{4}}{16(b-1)^{2}(1+c)^{2}\left(4(b-1)^{2}(1+c)+b^{2} e^{2}\right)}$ which is negative (both numerator and denominator are positive) since there is a negative sing in front of the ratio. Hence, the level of the profitsis lower under the ex-ante case.

\subsection{Ex-ante scenario - Oligopoly}

\subsubsection{Stage 2: Firms decide on output}

We calculate the First Order Conditions (FOCs) ${ }^{20} \frac{\partial \Pi_{i}}{\partial q_{i}^{*}}=a-2 q_{i}\left(1+c_{i}\right)-q_{j}=0$ and solving simultaneously with respect to $q_{i}$ we take

$$
\begin{gathered}
\bar{q}_{i}^{E A}=\frac{a\left(1+2 c_{j}\right)}{3+4 c_{j}+4 c_{i}\left(1+c_{j}\right)} \\
\Pi_{i}^{E A}=\left(\bar{q}_{i}^{E A}\right)^{2}\left(1+c_{i}\right)-\left(k_{i}-1\right)^{2}
\end{gathered}
$$

where the superscript $E A$ indicates the first scenario (ex-ante).

\subsubsection{Stage 1: Regulator decides for technology}

The Social Welfare is given by $S W^{E A}=b\left(C S^{E A}-D F^{E A}\right)+(1-b) P S^{E A}$ where $C S^{E A}=\frac{1}{2} \sum_{i=1}^{2} \bar{q}_{i}^{E A}, D F^{E A}=e\left(k_{i} \bar{q}_{i}^{E A}+k_{j} \bar{q}_{j}^{E A}\right)$ and $P S^{E A}=\sum_{i=1}^{2} \Pi_{i}^{E A}$ and from the FOC we obtain ${ }^{21}$

$$
\frac{\partial S W^{E A}}{\partial k_{i}}=2(b-1)\left(k_{i}-1\right)-\frac{b\left(a+2 a c_{j}\right) e}{3+4 c_{j}+4 c_{i}\left(1+c_{j}\right)}=0
$$

\footnotetext{
${ }^{20}$ The Second Order Condition (SOC) is satisfied $\frac{\partial^{2} \Pi_{i}}{\partial q_{i}^{2}}=-2\left(1+c_{i}\right)<0$.

${ }^{21}$ The SOC is $\frac{\partial^{2} S W^{*}}{\partial k^{2}}=2(b-1)<0, \forall b<1$.
} 
yielding the optimum technology

$$
\bar{k}_{i}^{E A}=1+\frac{a b\left(1+2 c_{j}\right) e}{2(b-1)\left(3+4 c_{j}+4 c_{i}\left(1+c_{j}\right)\right)}
$$

After the necessary substitutions the profits are

$$
\bar{\Pi}_{i}^{E A}=\left(\bar{q}_{i}^{E A}\right)^{2}\left(\left(\frac{4(b-1)^{2}\left(1+c_{i}\right)-b^{2} e^{2}}{4(b-1)^{2}}\right)\right)
$$

and the price is

$$
\bar{p}_{i}^{E A}=\frac{a\left(1+2 c_{i}\right)\left(1+2 c_{j}\right)}{3+4 c_{j}+4 c_{i}\left(1+c_{j}\right)}
$$

The emissions are given by $\bar{y}_{i}^{E A}=\bar{q}_{i}^{E A} \bar{k}_{i}^{E A}$ and $D F^{E A}=e \bar{y}_{i}^{E A}$. As usual we substitute the above equation into the $S W^{E A}$ and we take the final $S \bar{W}^{E A}$.

\subsection{Ex-post scenario}

\subsubsection{Stage 2: Regulator decides for technology - Oligopoly}

Like in the basic model, the regulator will decide on the level of the technology which maximises the social welfare. The FOC is equal to: ${ }^{22}$

$$
\begin{array}{ll}
\frac{\partial S W}{\partial k_{i}}= & 2(b-1)\left(k_{i}-1\right)-b e q_{i}=0, \\
\frac{\partial S W}{\partial k_{j}}= & 2(b-1)\left(k_{j}-1\right)-b e q_{j}=0,
\end{array}
$$

and solving simultaneously we have

$$
k_{i}^{E P}=1+\frac{b e q_{i}}{2(b-1)}, k_{j}^{E P}=1+\frac{b e q_{j}}{2(b-1)}
$$

where the superscript $E P$ indicates the ex-post case.

\footnotetext{
${ }^{22}$ The SOC is negative $(2(b-1))$ so, it guaranties the optimum value of $k$.
} 


\subsubsection{Stage 1: Firms decide on output}

After the substitution of $k_{i}^{E P}$ into the profit's equation we have $\Pi_{i}^{E P}=$ $q_{i}\left(a+\left(-1-c_{i}-\frac{b^{2} e^{2}}{4(b-1)^{2}}\right) q_{i}-q_{j}\right)$ and the FOCs are ${ }^{23}$

$$
\frac{\partial \prod_{i}^{E P}}{\partial q_{i}}=a+\left(-2-2 c_{i}-\frac{b^{2} e^{2}}{(b-1)^{2}}\right) q_{i}-q_{j}=0
$$

where the optimum level of output is

$$
\bar{q}_{i}^{E P}=\frac{4 a G^{4}\left(1+2 c_{j}\right)+2 a G^{2} b^{2} e^{2}}{4 G^{4} F+4 G^{2} b^{2}\left(2+c_{i}+c_{j}\right) e^{2}+b^{4} e^{4}}
$$

where $G=b-1, F=3+4 c_{j}+4 c_{i}\left(1+c_{j}\right)$. Moreover, the optimum level of technology (after the substitution) equals $\bar{k}_{i}^{E P}=\frac{2 a G^{3} b\left(1+2 c_{j}\right) e+a G b^{3} e^{3}}{4 G^{4} F+4 G^{2} b^{2}\left(2+c_{i}+c_{j}\right) e^{2}+b^{4} e^{4}}$ and similar we take the level of the emissions $\bar{y}_{i}^{E P}=\bar{q}_{i}^{E P} \bar{k}_{i}^{E P}$, the damage equation $D F^{E P}=e \bar{y}_{i}^{E P}$, the price $\bar{p}_{i}^{E P}=a-\bar{q}_{i}^{E P}-\bar{q}_{j}^{E P}$, the profits $\Pi_{i}^{E P}=$ $\bar{q}_{i}^{E P}\left(a+\left(-1-c_{i}-\frac{b^{2} e^{2}}{4(b-1)^{2}}\right) \bar{q}_{i}^{E P}-\bar{q}_{j}^{E P}\right)$ and the social welfare $S \bar{W}^{E P}$ (the last results are characterised by complex and long equations).

${ }^{23}$ The SOC is $\frac{\partial^{2} \Pi_{i}}{\partial q_{i}^{2}}=-2-2 c_{i}<0$. 


\section{$7 \quad$ References}

1. Aguilera, R.V. and Jackson, G. (2003). The cross national diversity of corporate governance: dimensions and determinants. Academy of Management Review, 28, 447-465.

2. Asproudis, E. and Gil-Moltó, M. J. (2015). Green trade unions: Structure, wages and environmental technology. Environmental and Resource Economics, 60, 165-189.

3. Asproudis, E. and Gil-Moltó, M. J. (2014). Pollution and environmentalists participation in Emissions Trading Systems. Srategic Behavior and the Environment, 4, 59-87.

4. Baldwin, R. (2011) 21st century regionalism: Filling the gap between 21st century trade and 20th century trade rules, Staff working paper ERSD, No. 2011-08

5. Bandyopadhyay, S., Lahiri, S. and Wall, H. J. (2012). Cross-border lobbying in preferential trading agreements: Implications for external tariffs and welfare. Review of International Economics, 20, 1034-1045.

6. Barron, A. (2011). Exploring national culture's consequences on international business lobbying. Journal of World Business, 46, 320-327.

7. Berman, E. and Bui, L. T. (2001). Environmental regulation and productivity: evidence from oil refineries. Review of Economics and Statistics, 83, 498-510.

8. Bernheim, D. and Whinston, M. (1986). Menu auctions, resource allocation, and economic influence. Quarterly Journal of Economics, 101, $1-31$. 
9. Bibas, R., Mejean, A. and Hamdi-Cherif, M. (2015). Energy efficiency policies and the timing of action: An assessment of climate mitigation costs. Technological Forecasting and Social Change, 90, 137-152.

10. Borras, S. and Edquist, C. (2013). The choice of innovation policy instruments. Technological Forecasting and Social Change, 80, 15131522.

11. Borzel, T. and Risse, T. (2000). When Europe hits home: Europeanisation and domestic change. European Integration Online Papers, Eiop, Vol.4, No.15.

12. Chao, H-P. and Wilson, R. (1993). Option value of emission allowances. Journal of Regulatory Economics, 5, 233-249.

13. Coen, D. (1999). The impact of U.S. lobbying practice on the European business-government relationships. California Management Review, 41, 27-44.

14. Conyon, M., Judge, W. Q. and Useem, M. (2011). Corporate Governance and the 2008-09 Financial Crisis. Corporate Governance: An International Review, 19, 399-404.

15. Damania, R. and Fredriksson, P. G. (2000). On the formation of industry lobby groups. Journal of Economic Behavior and Organization, 41, 315-336.

16. Denicolo, V. (1999). Pollution-reducing innovations under taxes or permits. Oxford Economic Papers, 51, 184-199.

17. Dubiel-Teleszynski, T. (2011). Nonlinear dynamics in a heterogeneous duopoly game with adjusting players and diseconomies of scale. Communications in Nonlinear Science and Numerical Simulation, 16, 296308. 
18. Elliott, E. D., Ackerman, B. A. and Millian, J. C. (1985). Toward a theory of statutory evolution: The federalization of environmental law. Journal of Law, Economics, and Organization, 1, 313-340.

19. Farazmand, A. (1999). Globalization and public administration. Public Administration Review, 59, 509-522.

20. Flores, R., Aguilera, R. V., Mahdian, and Vaaler, P. M. (2013). How well do supranational regional grouping schemes fit international business research models and quest. Journal of International Business Studies, 44, 451-474.

21. Freeman, R. E., Martin, K. and Parmar, B. (2007). Stakeholder capitalism. Journal of Business Ethics, 74, 303-314.

22. Friedman, M. (1962). Capitalism and Freedom. Chicago, University of Chicago Press.

23. Goulder, L. H. and Mathai. K. (2000). Optimal $\mathrm{CO}_{2}$ abatement in the presence of Induced Technological Change. Journal of Environmental Economics and Management, 39, 1-38.

24. Groll, T. and Ellis, C. J. (2013). A simple model of the commercial lobbying industry (No. 4110). CESifo Working Paper: Public Finance.

25. Grossman, G. and Helpman, E. (1994). Protection for sale. American Economic Review, 84, 833-850.

26. Hamilton, D.S. and Quinlan, J.P. (2011). The Transatlantic Economy : Annual Survey of Jobs, Trade and Investment between the United States and Europe. Centre for Transatlantic Relations, The Paul H. Nitze School of Advanced International Studies, Johns Hopkins University. Washington. Available at http://transatlantic.saisjhu.edu/publications/books/Transatlantic_Economy_2011/te_2011.pdf 
27. Hay, C. and Rosamond, B. (2002) Globalisation, European integration and the discursive construction of economic imperatives. Journal of European Public Policy, 9, 147-167.

28. Henning, C. R. and Kessler, M. (2012). Fiscal Federalism: U.S. History for Architects of Europe's Fiscal Union (January 10, 2012). Peterson Institute for International Economics Working Paper No. 2012-1. Available at SSRN: http://ssrn.com/abstract=1982709 or http://dx.doi.org/10.2139/ssrn.198

29. Helfand, G. E. (1991). Standards versus Standards: The Effects of Different Pollution Restrictions. The American Economic Review, 81, $622-634$.

30. Hillman, A. J. (2003). Determinants of political strategies in U.S. multinationals, Business and Society journal, 42, 455-484.

31. Hiriart, Y., Martimort, D. and Pouyet, J. (2004). On the optimal use of ex ante regulation and ex post liability. Economics Letters, 84, 231-235.

32. Holman, C. (2009). Lobbying reform in the United States and the European Union: progress on two continents. Interest Groups and Lobbying, citizen.org (Public citizen), pg 267-296.

33. Holzinger, K., Knill, C. and Sommerer, T. (2008). Environmental policy convergence: The impact of international harmonization, transnational communication, and regulatory competition. International Organization, 62 , 553-587.

34. Innes, R., and Bial, J.J. (2002). Inducing innovation in the environmental technology of oligopolistic firms. Journal of Industrial Economics, 50, 265-287.

35. Jaffe, A. B. and Stavins, R. N. (1995). Dynamic incentives of environmental regulations: The effects of alternative policy instruments on 
technology diffusion. Journal of Environmental Economics and Management, 29, 43-63.

36. Kakabadse, A. P. and Kakabadse, N. K. (2012). Beyond Lobbying: Analysis of European Wide Corporate/Government Relations. Report funded by Academy of Business in Society, October.

37. Kakabadse, N.K., Kakabadse, A., Kouzmin, A. and Pesqueux, Y. (2013). Rethinking the ontology of the shareholder model of the corporation. Society and Business Review, 8, 55-70.

38. Kee, Hiau Looi. (2002). Markups, returns to scale, and productivity: A case study of Singapore's manufacturing sector. World Bank Policy Research Working Paper 2857.

39. Keohane, N. O. (2002). Environmental policy and the choice of abatement technique: evidence from coal-fired power plants. Paper presented at 2nd world congress of environmental and resource economists, June 2002, Monterrey, CA

40. Kennedy, P. W. (1999). Learning about environment damage: Implications for emissions trading. Canadian Journal of Economics, 32, 1313-1327.

41. Kennedy, P., and Laplante, B. (1999) Environmental policy and time consistency: emission taxes and emissions trading. in Petrakis, E., Sartzetakis, E. S., and Xepapadeas, A. (ed.) Environmental regulation and market power. Edward Elgar: U.K.

42. Khan, N., Asproudis, E. and Kakabadse, N. K. (2014). Transatlantic regulatory timing of policy innovations: The case of renewable energy. In Kakabadse, A. and Schepers, S., (Eds.) Rethinking the Future of Europe: A Challenge of Governance. Palgrave Macmillan. 
43. Knyght, R., Kakabadse, N., and Kakabadse, A. P. (2011) When rules and principles are not enough: insiders' views and narratives on the global financial crises. Journal of Change Management, 11, 45-67.

44. Kolstad, C., Ulen, T., and Johnson, G. (1990). Ex post liability for harm vs. ex ante safety regulation: substitutes or complements? American Economic Review, 80, 888-901.

45. Magee, S.P., Brock, W.A., and Young, L. (1989). Black hole tariffs and endogenous policy theory: Political economy in general equilibrium. Cambridge University Press, Cambridge.

46. Matten, D., and Moon, J. (2008). "Implicit" and "explicit" CSR: A conceptual framework for a comparative understanding of corporate social responsibility. Academy of management Review, 33, 404-424.

47. Marusca, L., and Irimies, C. (2013) Models of lobby in Europe. Journal of Media Research - Revista de Studii Media, 1, 56-62.

48. Montero, J. P. (2002). Permits, standards, and technology innovation. Journal of Environmental Economics and Management, 44, 23-44.

49. Onetti, A., Zucchella, A., Jones, M.V. and McDougall-Covin, P.P.(2012). Internationalization, innovation and entrepreneurship: business models for new technology-based firms. Journal of Management and Governance, $16,337-368$.

50. Parry, I. W., Pizer, W. A. and Fischer, C. (2003).How large are the welfare gains from technological innovation induced by environmental policies?. Journal of Regulatory Economics, 23, 237-255.

51. Puller, S. (2006). The strategic use of innovation to influence regulatory standards. Journal of Environmental Economics and Management, 52, 690-706. 
52. Requate, T. (2005a).Dynamic incentives by environmental policy instruments - a survey. Ecological Economics, 54, 175-195.

53. Requate, T. (2005b).Timing and commitment of environmental policy, adoption of new technology, and repercussions on R\&D," Environmental and Resource Economics, 31, 175-199

54. Schepers, S. (2010) Business-government relations: beyond lobbying. Corporate Governance, 10, 475-483.

55. Shadbegian, R. J. and Gray, W. B. (2006). Assessing multi-dimensional performance: environmental and economic outcomes. Journal of Productivity Analysis, 26, 213-234.

56. Shaffer, B. (1995). Firm-level responses to government regulation: theoretical and research approaches. Journal of Management, 21, 495-514.

57. Shavell, S. (1984). A model of the optimal use of liability and safety regulation. RAND Journal of Economics, 15, 271-280.

58. Soltani, B. (2013). The anatomy of corporate fraud: A comparative analysis of high profile american and european corporate scandals. Journal of Business Ethics, 120, 1-24.

59. Spar, D. L. and La Mure, L. T. (2003). The power of activism: assessing the impact of NGOs on global business. California Management Review, 45, 78-101.

60. Srivastava, R. K., Jozewicz, W. and Singer, C. (2001). $\mathrm{SO}_{2}$ scrubbing technologies: a review. Environmental Progress, 20, 219-227.

61. Tobey, J. A. (1990). The effects of domestic environmental policies on patterns of world trade: An empirical test. Kyklos, 43, 191-209. 
62. United Nations (2012). World Economic Situation and Prospects 2012. A join $t$ report produced by UNDESA and UNTAD, New York, NY available at United Nations (2012a). World Economic Situation and Prospects 2012, United Nations.

63. Van den Bergh, J. C. J. M. (2013). Environmental and climate innovation: limitations, policies and prices. Technological Forecasting and Social Change, 80, 11-23.

64. van Essen, M., Engelen, P.J. and Carney, M. (2013). Does "good" corporate governance help in a crisis? The impact of country- and firm-level governance mechanisms in the European financial crisis. Corporate Governance: An International Review, 21, 201-224.

65. Vogel, D. (2003). The hare and the tortoise revisited: The new politics of consumer and environmental regulation in Europe. British Journal of Political Science, 33, 557-580.

66. Weymouth, S. (2011). The microeconomic determinants of lobbying and political influence: A multilevel approach. Working Paper. George Town University.

67. Yackee, J. W. and Yackee, S. W. (2006). A bias towards business? Assessing interest group influence on the US bureaucracy. Journal of Politics, 68, 128-139. 